\title{
The outcome of femtosecond laser in situ keratomileusis compared to conventional laser in situ keratomileusis in myopic patients
}

\author{
Sarah Gamal, Ismail Mousa, Osama Ali, Mourtada Ahmed \\ Ophthalmology Department Faculty of Medicine Sohag University
}

\begin{abstract}
Introduction:This is a prospective comparative clinical study conducted to assess the safety, effectiveness, and complications of Intralase femtosecond laser (FSL) compared to Moria M2 microkeratome (MK) in high myope.

Methods :This study consisted of 51 myopic eyes, divided into two groups( A \& B) . Twenty-five eyes in group A in which the flap was created by Intralase FSL, while twenty-six eyes in group B in which the flap was created by Moria M2 MK. Refractive, keratometric and flap complications were compared preoperative and 6 months postoperative by using the intraoperative subtraction pachymetry . (Scheimpflug imaging (CSO, Florence, Italy).

Results:No substantial difference was found as regarding postoperative manifest sphere, astigmatic and keratometry. In group A mean postoperative actual flap thickness was $98.12 \pm 16.1 \mu \mathrm{m}$ and in group B it was $100.6 \pm 20.1 \mu \mathrm{m}$ with statistically significant difference ( $\mathrm{P}$ value 0.001 ).

Conclusion: Both the femtosecond laser and the mechanical microkeratome are safe and effective in correcting myopia, with no statistically significant difference during 6month follow-up between the two groups. The femtosecond laser has better flap creation than the microkeratome .
\end{abstract}

Key words: FSL, Maria M2 ,Myope

\section{Introduction}

LASIK (laser-assisted in situ keratomileusis) is a form of refractive surgery intended to correct myopia, hyperopia, and astigmatism, usually referred to as laser eye surgery or laser vision correction. The LASIK surgery is conducted by an ophthalmologist who uses a laser and microkeratome to reshape the cornea of the eye to boost visual acuity.(1) In most cases LASIK presents a permanent alternative to eyeglassses or contact lenses.(2)
Production of LASIK flaps can be achieved by either a mechanical microkeratome or a femtosecond laser. Five femtosecond (FS) lasers for LASIK are officially FDA-lice-nsed: Intralase (Abbott Medical Optics), Vis-uMax (Carl Zeiss Meditec AG), Femtec (Technolas Perfect Vision), Femto LDV (Ziemer Ophthalmic Systems AG), and Wavelight FS200 (Alcon Sur-gical). Ultrashort laser pulses are used by all FS systems, and Photodisruption is the basis of the contact cycle for cutting corneal 
tissues, but it is imp-ortant to understand substantially diff-errent technical specifics and clinic-al experience. (3)

The flap creation process is different between the Intralase femtosecond laser and most mechanical microkeratomes include-ng Moria M2. With the latter, the eye is fixed with a suction ring and the cornea is not applanated before the cut is made. During the cutting process, the cornea bulges out of the ring and is compressed by the moving applanation surface. The corneal cut is made with a moving blade. In this case, biomechanical parameters (e.g., corn-eal rigidity, total corneal thickness) can influence the parallelism and thickness of the flap. In addition, the suction of the femtosecond laser head is less than with a mechanical microkeratome, which is more comfortable for the patient(4).

\section{PATIENTS AND METHODS}

Patients: Fifty_one eyes of twenty_ six patients that were diagnosed as having myopia were eligible for this study that has been conducted in the Future center for LASIK and refractive surgery, in the period from January 2018 to August 2018.

Study design: This study was a prospective non randomized comparative clinical trial.

Inclusion criteria: This study included 51 myopic eyes that had thinnest central Pachymetry equal to or more than $\geq 480$ microns, mean age[18:48] years old, mean keratometry between [39: 48] diopter, clear central cornea, and uncorrected Visual acuity $<0.3$ Log MAR or Snellen 20/40.

Exclusion criteria: Eyes with the following criteria was excluded from the stu$\mathrm{dy}$, keratoconus, history of atopy or ocular allergic disorders, previous corneal refractive surgeries, and partic-ipants
The outcome of femtosecond laser in Sarah Gamal Fathi

who did not complete their follow up period.

Methodology: The research divided myopic eyes into two groups (A \&B )according to the method of operation.

Group A, twenty-five eyes of thirteen patients had Femtosecond LASIK, four were males and nine were females, with age ranged from (18:48) years. Twelve patients had bilateral Femtosecond LASIK and one patient has unilateral One. Group B, twenty-six eyes of thirteen patients had Conventional Lasik. Seven were males and six were females, with age ranged from $(25: 45)$ years.

\section{Preoperative Evaluation:}

Full ophthalmologic examination had been performed on all eyes before surgery included the following: uncorrected visual acuity (UCVA) in Log MAR, manifest and cycloplegic refraction, best corrected vis-ual acuity (BCVA) in Log MA, slit-lamp biomicroscopy examination, fundus examination, and corneal topography.

Informed written consent from patients had been obtained after obtaining the approval of the ethical committee of Sohag faculty of medicine.

\section{Operative technique:}

After topical anesthesia with proparacaine hydrochloride (Benox) of 0.4 percent, 7 percent povidone-iodine solution was added to the skin and conjunctive and a sterile surgical drape and eyelid speculum were placed.

The Moria M2 microkeratome was used to build the flap in the Microkeratom commu-nity. According to Moria nanagram, the cu-tting head (90$120 \mu \mathrm{m})$, and the suction rings $(7.5 \mathrm{~mm}$ $8 \mathrm{~mm})$. In the microkera-tome community (group B), The Moria M2 microkeratome was used to build the flap. According to Moria nomogram, the cutting head $(90-120 \mu \mathrm{m})$, and the suction rings $(7.5 \mathrm{~mm}-8 \mathrm{~mm})$. A soft 
corneal suction ring is added to the eye and the eye remains in place. Occasionally, this phase in the procedure may trigger tiny blood vessels to burst, leading to bleeding or subconjunc-tival hemorrhage in the eye's white (sclera), a harmless side effect that will resolve within several weeks. Enhanced suction causes the treated eye to have a temporary dimmer of vision. When the eye is immobi-lized, the cutting through the corneal epithelium and Bowman's layer produces a flap. This method is done using a metal blade with a mechanical microkeratome.

In the Intralase FS150 community (group A), The flap was generated using Intralase femtosecond laser. The laser intensity was set at $0.75 \mathrm{UJ}$, and the frequency of repetit-ion at $150 \mathrm{KHz}$. The length of the pulses was 600 to 800 femtoseconds. We produ-ced superior hinged flaps with a diameter of $8.5 \mathrm{~mm}$. The separations from line and position were $8.0 \mathrm{um}$. The lateral cut angle is 90 , 50. The pocket starting depth is $180 \mathrm{um}$, and width of the pocket is $0.2 \mathrm{~mm}$. The Intralase femtosecond laser software prod-uces a circular cleavage plane beginning at 1 side of the cornea and moving across the cornea using a pattern of raster (back and force). It then generates a flap edge of a programmable angle (side cut angle) using a circumferential pattern of gradually shallower pulses. To construct the hinge a predefined arc is left uncut along the edge. The whole procedure is carried out by means of a glass applanation plate attached to the eye with a low pressure suction ring.

In both classes, once the flap was formed using either process, it was raised with a spatula, the stromal bed was dried with a sponge, and the ablation was performed using a traditional treatment algorithm using the VISX S4IR wave. The stroma was then rinsed with balanced salt solution, and a cannula gently placed the flap back in
The outcome of femtosecond laser in Sarah Gamal Fathi

place. At the end of the treatment one drop of the ophthalmic solution of moxifloxacin hydrochloride, prednisolone and tear replacement was added

\section{Postoperative Analysis :}

In general, patients are given a course of antibiotics (moxifloxacin hydrochloride), anti-inflammatory eye drops (prednisolone acetate 0.1), and artificial tears. They are done in the weeks following surgery.

Relaxation is advised for patients, and dark eyeglasses are provided to shield their eyes from bright lights and sometimes protective goggles to avoid eye rubbing while sleeping and minimize dry eyes. We should also use preservative-free tears to moisturize the eyes and follow instructions for drops on prescription. Reduces the risk of complications, patients should be adequately advised on the value of effective postoperative care by their surgeons.

Patients were tested on the 1 st and 2 nd week postoperative-months 2,4 and 6 at each visit the following parameters will be evaluated, UCVA, change in refraction, pentacam, and flap complication .

Statistical Analysis: Data was analyzed using STATA intercooled version 12.1. Quantitative data was represented as mean, standard devia-tion. Data was analyzed using student t-test to compare means of two groups. When the data was not normally distributed Mann-Whitney test was used to compare two groups. Qualit-ative data was presented as number and perce0ntage and compared using either Chi square test or fisher exact test. Graphs were produced by using Excel program. $P$ value was considered signif-icant if it was less than 0.05 .

\section{Results}

51 myopic eyes of 26 patients had been included in this study with age range 18 : 
SOHAG MEDICAL JOURNAL

Vol. 24 No. 3 July 2020

48 years and mean age of $4.92 \pm 3.3$ years. 11 patients were males $(42.31 \%)$ and 15 patients were females $(57.69 \%)$. The patients were divided into two classes A \& B. Group A mean age was $26.08 \pm 9.90$ years, group B mean age was $31.00 \pm 6.60$ years . (Table 1 )

\begin{tabular}{|l|l|l|l|}
\hline & $\begin{array}{l}\text { Femtosecond } \\
\text { Group (A) }\end{array}$ & $\begin{array}{l}\text { Conventional } \\
\text { Group (B) }\end{array}$ & $\begin{array}{l}\text { P } \\
\text { value }\end{array}$ \\
\hline $\begin{array}{l}\text { Age } \\
\text { Mean } \pm \text { SD } \\
\text { Median } \\
\text { (range) }\end{array}$ & $\begin{array}{l}26.08 \pm 9.90 \\
23(18-48)\end{array}$ & $\begin{array}{l}31.00 \pm 6.60 \\
28(25-45)\end{array}$ & 0.14 \\
\hline $\begin{array}{l}\text { Gender } \\
\text { Females } \\
\text { Males }\end{array}$ & $\begin{array}{l}9(69.23 \%) \\
4(30.77 \%)\end{array}$ & $\begin{array}{l}6(46.15 \%) \\
7(53.85 \%)\end{array}$ & 0.23 \\
\hline
\end{tabular}

Demographic data of studied population In group A : UCVA changed from $1.41 \pm 0.26$ preoperative to $0.30 \pm 0.17$ postoperative for 6 months follow- up .

In group $\mathrm{B}$ : UCVA changed from $1.28 \pm 0.33$ preoperative to $0.30 \pm 0.15$ postoperative for 6 months follow- up .

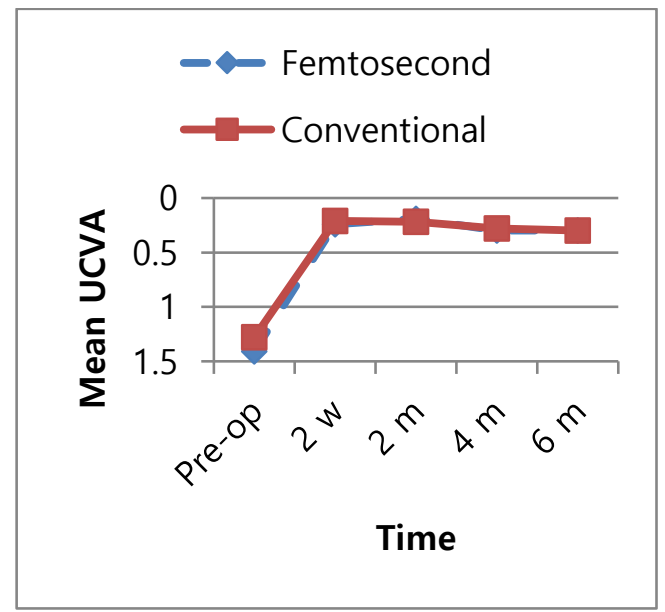

Figure1: A statistical diagram shows changes in UCVA in 2 groups for a period of 6 months

In group A, preoperative sphere was ($8.09) \pm 2.38$, at 6 months changed to ($0.09) \pm 0.39$, while in group $B$, preoperative sphere was $(-8.49) \pm 1.48$, at 6 months changed to $(-0.03) \pm 0.62$.

In group $\mathrm{A}$, mean preoperative cylinder was $(-2.14) \pm 1.38$, at 6 months changed to $(-0.21) \pm 0.16$, and in group $B$, mean preoperative cylinder was $(-1.60)$
The outcome of femtosecond laser in Sarah Gamal Fathi

\pm 0.99 , at 6 months changed to $0.13 \pm 0.28$.

In group $\mathrm{A}$, mean preoperative $\mathrm{K} 1$ $43.29 \pm 2.40$, at 6 months changed to $39.41 \pm 2.94$, and in group $B$, mean

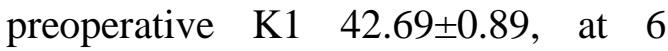
months changed to $38.32 \pm 3$.

In group $\mathrm{A}$, mean preoperative $\mathrm{K} 2$ $44.41 \pm 1.96$, at 6 months changed to $40.51 \pm 2.89$, while in group $B$, mean preoperative $\mathrm{K} 243.71 \pm 0.97$, at 6 months changed to $39.42 \pm 3.19$.

In group $\mathrm{A}$, preoperative Avg $\mathrm{K}$ $43.85 \pm 1.92$, at 6 months changed to $39.96 \pm 2.90$, and in group B, preoperative Avg $\mathrm{K} 43.17 \pm 0.88$, at 6 months changed to $39.06 \pm 3.19$.

In group A, (CCT) changed from $529.28 \pm 19.59$ preoperative to $443.52 \pm 33.34$ postoperative for 6 months follow up, and in group B, (CCT) changed from 538.27 \pm 21.80 preoperative to $419.67 \pm 36.88$ postoperative for 6 months follow up.

Two eyes in the Intralase community complained of diffuse grade I lamellar keratitis, which developed postoperatively on the third day and resolved in 3 weeks. It was treated with frequent topical steroids and completely resolved without any visual effect and Three eyes in the MK group developed epithettlial defects and were managed with contact lens bandage. Two eyes in the intralase group and four eyes in the MK group developed vision-free micro stria and no cases in both groups require improvement.

\section{DISCUSSION}

LASIK flaps can be produced either by a mechanical MK or an FSL.(5) Recently developed automated MKs with single-use head have advantages over conventional metal heads, such as no need for assembly, improved flexibility and reduced risk of infection.(6) With increasing understanding of corneal biomechanics, the creation of 
thinner and more reliable flaps led to the development of more precise MKs and a bladless method of making flaps. Healthy MKs are associated with precise cuts, simple adjustment, less variation of the flaps and fewer complications. There have been reports of various studies comparing MK and the development of femtosecond flaps but with varying performance. Several studies indicated that the development of LASIK flaps with the FSL resulted in better UDVA and faster visual recovery, lower postoperative astigmatism and trefoil, lower spherical aberration, faster corneal sensitivity recovery, and some contrast sensitivity. Others also indicated that visual results during the first 6 months after LASIK are not affected by the flap formation method.(7)

In our research Intralase femtolasik and Moria MK techniques there is no substantial difference in UCVA, sphere, cylinder, protection, efficacy and flap complication between two groups. the proportion of eyes achieving postoperative UDVA of 20/25, 20/20 and 20/16 were higher in Intralase group compared to MK group .Moreover, the Intralase group had more patients who were within $\pm 0.50 \mathrm{D}$ and $\pm 0.25 \mathrm{D}$ of target refraction compared to the MK group. In addition there was no loss of lines in either group. However, the gain of one line was more pronounced in Intralase group compared to $\mathrm{MK}$ group. our results were more or less similar to those reports. Huhtala A et al.(9)analyzed the results of 266 myopic eyes which were operated with Moria M2 singleuse head 90 MK. After 4 weeks follow up, $92.4 \%$ of eyes were within $\pm 0.50 \mathrm{D}$ of target refraction, $97.3 \%$ eyes achieved UCVA $\geq 20 / 40$. No eyes lost $\geq 2$ Snellen lines.
The outcome of femtosecond laser in Sarah Gamal Fathi

Regarding Intralase, Blum $\mathrm{M}$ et al.(10) treated myopia in 32 eyes with used the Intralase FSL . After 3 months, all eyes had CDVA of 20/25 and UDVA of $20 / 40,91 \%$ of eyes reached UDVA of $20 / 20$ or better, $94 \%$ of eyes were within $\pm 0.50 \mathrm{D}$ of the planned correction. Similar results reported by Issa A et al.(11)

Montes MR et al.(12)stated that the reason for the better results found in improved CDVA using IntraLase versus LASIK may be the decrease in use of irrigation with femtolaser. Considering that laser ablation rates vary with tissue hydration, by avoiding the need for irrigation tissue hydration may be more standardized with femtolaser than with mechanical microkeratomes. Another explanation given by Durrie DS et al.(13) and Kezirian GM et al.(8)was the reduction in the overall induced astigmatism in spherical treatments with the IntraLase. However, other studies were unable to prove significant differences in astigmatic refractive outcomes between the two groups. $(14,15)$ The Flattest K, the steepest $\mathrm{K}$ and Mean K showed a significant decline in both categories, with no significant difference between them .

During the follow-up period, the thickness of the thinnest position was decreased slightly in group A, while during the follow-up period there was a significant decrease in the thickness of the thinnest position in group B with a remarkable significant difference between the two groups.

Mechanical MK were known to have a low level of precision in creating corneal flaps of accurate thickness and have typically demonstrated a standard deviation of flap thickness between 18 and $24 \mu \mathrm{m}$.(16) Others reported standard deviation of flap thickness achieved by mechanical $\mathrm{MK}$ in the range of \pm 20 to $\pm 40 \mu \mathrm{m}$.(17) Recent studies found that 
the FSL created flaps show less variability in flap thickness to be within \pm 20 $\mu \mathrm{m}$ of the intended result. $(17,18)$ Huhtala A et al.(19)measured the corneal thickness of 266 myopic eyes by ultrasonic pachymetry and Moria M2 singleuse head 90was used to create a flap with a thickness of $120 \mu$ m.Mean corneal flap thickness was $115.4 \pm 12.5$ $\mu \mathrm{m}(73-147 \mu \mathrm{m})$.

They concluded that as with most MKs, the single-use head $90 \mathrm{MK}$ cut thinner flaps than were intended. The range of the cuts was relatively wide. However, thin flaps did not increase the rate of flap related complications. Undercutting (i.e. cutti-ng corneal flaps that are thinner than intended) appears to be the most common problem with most MKs other than the Amadeus. Thin flaps are more liable to buttonholes and cause more complicated handling during surge-ry.(19)

Although the M2 single use head tends to cut less than the manufacture expected, its cuts showed smaller variability comparable not only to other Moria heads but also to other MKs with different heads . Literature reports have been published on the Intralase and Visumax showing that these FSLs have better flap thickness predictability and better visual outcomes than mechanical MKs. $(20,21)$ Vaddavalli and Yoo(22)summarized this by stating that the femtosecond laser was capable of creat-ing uniform,predictable corneal flaps that could be personalized in design;a-dditionally, the side-cut angle could be varied at the operator's discretion. Obvious advantages were that thicker flaps resulted in decreased stromal bed thickness, which increased the risk for interlayer cloudiness and iatrogenic corneal ectasia. Therefore, patients should be carefully evaluated for proper design of the corneal flap to minimize post-opera-
The outcome of femtosecond laser in Sarah Gamal Fathi

tive complications and the need for additional surgery.

\section{REFERENCES}

1. Menezo JL, Periz-Martinez C, Cisneros-Lanuza AL, MartinezCosta R (2004). "Rate of cataract formation in 343 highly myopic eyes after implantation of 3 types of phacic intraocular lenses". J Refract Surg. 20: 317-324.

2. Torun; et al. (2013). "Posterior chamber phacic intraocular lens to correct myopia:long-term follow-up". J Cataract Refract Surg. 39(7): 10231028. doi:10.1016/j.jcrs.2013.01.041.

3. Randle RJ (1988). "Responses of myopes to volitional control training of accommodation". Ophthalmic Physiol Opt. 8 (3): 333340. doi:10.1111/j.14751313.1988.tb01063.x. PMID 3269512.

4. Gallaway M, Pearl SM, Winkelstein AM, Scheiman M; Pearl; Winkelstein; Scheiman (1987). "Biofeedback training of visual acuity and myopia: A pilot study". Am J Optom Physiol Opt. 64 (1): 6271. doi:10.1097/00006324-19870100000011. PMID 3826280.

5. Suarez E, Torres F, Vieira JC, Ramirez E, Arevalo JF; Torres; Vieira; Ramirez; Arevalo (October 2002). "Anterior uveitis after laser in situ keratomileusis". J Cataract Refract Surg. 28 (10): 17938. doi:10.1016/S0886-3350(02)013640. PMID 12388030.

6. Boes DA, Omura AK, Hennessy MJ; Omura; Hennessy (December 2001). "Effect of high-altitude exposure on myopic laser in situ keratomileusis". J Cataract Refract Surg. 27 (12): $1937-$ 41. doi:10.1016/S0886-3350(01)010744. PMID 11738908.

7. http://www.fda.gov/MedicalDevices/Pr oductsandMedicalProcedures/Surgerya ndLifeSupport/LASIK/ucm061354.htm

8. Kezirian GM, Stonecipher KG. Comparison of the IntraLase FSL and 
mechanical keratomes for laser in situ keratomileusis. J Cataract Refract Surg. 2004;30(4):804-811.

9. Huhtala A, Pietilä J, Mäkinen P, Suominen S, Seppänen M, Uusitalo H. Corneal flap thickness with the Moria M2 single-use head 90 MK. Acta Ophthalmol Scand. 2007;85(4):401406.

10. Blum M, Kunert K, Gille A, Sekundo W. LASIK for myopia using the Zeiss Visumax FSL and MEL 80 excimer laser. J Refract Surg. 2009;25(4):350-356.

11. Issa A, AL Hassany U. FSL flap parameters and visual outcomes in laser in situ keratomileusis. J Cataract Refract Surg. 2011;37:665-674.

12. Montés-Micó RI, RodríguezGalietero A, Alió JL. FSL versus mechanical Keratome LASIK for myopia. Ophthalmology. 2007;114:6268.

13. Durrie DS, Kezirian GM. FSL versus mechanical keratome flaps in wavefront-guided laser in situ keratomileusis; prospective contralateral eye study. J Cataract Refract Surg. 2005;31:120-126.

14. Li H, Sun T, Wang M, Zhao J. Safety and effectiveness of thin flap LASIK using a FSL and MK in the correction of high myopia in Chinese patients. J Refract Surg. 2010;26(2):99106.

15. Calvo R, McLaren JW, Hodge DO, Bourne WM, Patel SV. Corneal aberrations and visual acuity after laser in situ keratomileusis: FSL versus
The outcome of femtosecond laser in Sarah Gamal Fathi

mechanical

MK. Am $\mathrm{J}$

Ophthalmol. 2010;149(5):785-793.

16. Vaddavalli PK,Yoo SH.FSL in_situ Keratomileusis flap configurations.Curr Open Ophthalmol.2011 jul;22(4):24550

17. Kim J-H, Lee D, Rhee KI. Flap thickness reproducibility in laser in situ keratomileusis with a FSL: optical coherence tomography measurement. J Cataract Refract Surg. 2008;34:132-6.

18. Aslanides IM, Tsiklis NS, Astyrakakis NI, Pallikaris IG, Jankov MR. LASIK flap characteristics using the Moria M2 MK with the 90-micron single use head. J Refract Surg. 2007 Jan;23(1):45-9.

19. Huhtala A, Pietilä J, Mäkinen P, Suominen S, Seppänen M, UusitaloH . Corneal flap thickness with the Moria M2 single-use head 90 MK. Acta Ophthalmol Scand. 2007 Jun;85(4):401-6.

20. Reinstein DZ1, Carp GI, Archer TJ, Gobbe M. Transitioning from mechanical microkeratome to femtosecond laser flap creation: visual outcomes of an experienced and a novice LASIK surgeon. JCataract Refract Surg. 2012;38(10):1788-95. Oct

21. Hyunseok A, Jin KK, Chang KK, Gyu HH. Comparison of laser-in-situ keratomileusis flaps created by 3 FSLs and a MK. J Cataract Refr Surg. 2011;37:349-57.

22. Vaddavalli PK, Yoo SH. Femtosecond laser in-situ keratomileusis flap configurations.curr 0pen ophthalmol 2011;22(4):245-25 